REVESCO. Revista de Estudios Cooperativos ISSN: $1885-8031$

http://dx.doi.org/10.5209/REVE.59769

\title{
Gestión del conocimiento y competitividad en las cooperativas con sección de ahorro y crédito
}

\author{
Adalberto Escobar Castillo ${ }^{1}$, Gabriel Velandia Pacheco ${ }^{2}$ y Evaristo Navarro Manotas ${ }^{3}$
}

Recibido: 10 de mayo de 2017 / Aceptado: 27 de diciembre de 2017

Resumen. La naturaleza social de las cooperativas no significa que sus procesos deban ser ineficientes; por el contrario, en ellas han de existir políticas que permitan el establecimiento de ventajas competitivas. Por otro lado, en la economía post industrial el conocimiento se ha transformado en un activo relevante. En consecuencia, la investigación tiene como objetivo analizar la relación entre la gestión del conocimiento y la competitividad en las cooperativas de ahorro y crédito de Barranquilla. Para ello, se fundamenta en un enfoque racionalista crítico, paradigma cuantitativo, alcance correlacional y diseño no experimental transversal. Para la técnica, se realizó una encuesta a través de un cuestionario aplicado a los gerentes de 30 cooperativas de ahorro y crédito, las cuales fueron seleccionadas de acuerdo a un muestreo aleatorio simple y los datos fueron analizados mediante herramientas estadísticas. Los resultados demarcan la presencia de alineamientos que propenden por la creación, identificación, adquisición, clasificación, almacenamiento, aplicación, actualización y transferencia del conocimiento; sin embargo, no se presentan relaciones considerables entre estos procesos y el desarrollo de estrategias para la determinación de los factores clave de éxito; por este motivo, se concluye que en el contexto de las instituciones estudiadas, no existe evidencia empírica que soporte los fundamentos teóricos relacionados con la influencia de la administración de los activos intangibles, con respecto al desarrollo de competencias distintivas. Finalmente, se construyen las bases para la realización de estudios que busquen el fortalecimiento de las organizaciones solidarias a partir de la visualización de procesos sistemáticos que, asentados en las capacidades de aprendizaje organizacional, coadyuven a la obtención de una posición competitiva en el mercado.

Palabras clave: Factores clave de éxito; Estrategias competitivas; Aprendizaje organizacional; Capital intelectual; Economía solidaria.

Claves Econlit: D23; D83; M10; M15.

\section{[en] Knowledge management and competitiveness in cooperatives with section of savings and credit}

\footnotetext{
1 Universidad de la Costa CUC, Colombia

Dirección de correo electrónico: aescobar2@cuc.edu.co.

2 Universidad de la Costa CUC, Colombia

Dirección de correo electrónico: gvelandi1@cuc.edu.co.

3 Universidad de la Costa CUC, Colombia

Dirección de correo electrónico: enavarro3@cuc.edu.co.
}

Abstract. The social nature of cooperatives does not mean that their processes should be inefficient; on the contrary, they should have policies that allow the establishment of competitive advantages. On the other hand, in the post-industrial economy, knowledge has become a relevant asset. Consequently, 
research aims to analyse the relationship between knowledge management and competitiveness in credit unions in Barranquilla. For this purpose, it is based on a critical rationalist approach, quantitative paradigm, correlational scope and non-experimental transversal design. For the technique, a survey was conducted through a questionnaire applied to managers of 30 credit unions, which were selected according to a simple random sampling and the data were analyzed using statistical tools. The results indicate the presence of alignments aimed at creating, identifying, acquiring, classifying, storing, applying, updating and transferring knowledge; however, there are no significant relationships between these processes and the development of strategies for determining the key success factors; for this reason, it is concluded that in the context of the institutions studied, there is no empirical evidence that supports the theoretical foundations related to the influence of intangible asset management. Finally, the foundations are built for carrying out studies that seek to strengthen solidarity organizations based on the visualization of systematic processes that, based on organizational learning skills, contribute to obtaining a competitive position in the market.

Keywords: Key success factors; Competitive strategies; Organizational learning; Intellectual capital; Solidarity economy.

Sumario. 1. Introducción. 2. Perspectiva teórica de la gestión del conocimiento. 3. Constructo teórico de la competitividad empresarial. 4. Factores clave de competitividad en el contexto de las cooperativas. 5. Aspectos metodológicos de la investigación. 6. Análisis de resultados. 7. Conclusiones. 8. Referencias bibliográficas.

Cómo citar: Escobar Castillo, A., Velandia Pacheco, G. y Navarro Manotas, E. (2018) Gestión del conocimiento y competitividad en las cooperativas con sección de ahorro y crédito. REVESCO. Revista de Estudios Cooperativos, Primer Cuatrimestre, $\mathrm{N}^{\mathrm{o}} 127$, pp. 90-115. DOI: 10.5209/REVE.59769.

\section{Introducción}

Las organizaciones, se presentan en la sociedad como agentes integrados por recursos y capacidades, cuyo fin se establece en la satisfacción de las necesidades emanadas por los Stakeholders, a partir de la generación de beneficios que transcienden más allá de la esfera financiera. En efecto, las empresas deben inclinarse por el desarrollo sostenible de la sociedad a través de la implementación de estrategias administrativas que busquen responder los interrogantes básicos de la economía, con un alto grado de responsabilidad social.

No obstante a la notable relación que acaece entre los diferentes actores que convergen en los sistemas económicos, las dinámicas de la revolución industrial demarcaron las fallas existentes entre el sector privado y el público, en cuanto a la satisfacción de las necesidades emanadas por aquellos agentes de mayor vulnerabilidad de la sociedad. Para Otálora et al. (2016) este escenario sentó las condiciones necesarias para el surgimiento de una nueva y compleja estructura organizacional, la cual es abordada por Castilla et al. (2016) como un tipo de organización societaria, que posee objetivos que confluyen de la intersección entre estas dos divisiones económicas.

Dentro de las instituciones que integran el sector solidario, el cooperativismo se ha ubicado como una unidad básica de producción a través de la cual los agentes que integran los mercados buscan satisfacer los diferentes problemas que se presentan en la sociedad, constituyéndose según Bastidas y Amat (2014) en un importante agente de desarrollo socio empresarial. Lo descrito anteriormente posee fundamento en la medida en que estas instituciones ejecutan actividades 
comerciales de diversa índole, a fin de subsanar carencias sociales representadas en salud, vivienda, educación, trabajo y todos aquellos aspectos que propenden por el bienestar de la comunidad en general.

De hecho, el sector cooperativo se ha transformado en una fuerza económica y social que integra alrededor de mil millones de personas a nivel mundial. Para el año 2009, el tercer sector europeo se encontraba constituido por 160.000 cooperativas que integraron 123 millones de asociados y generaron más de 5.4 millones de empleos (Monzón, 2012). El escenario cooperativo del viejo continente demuestra que estas instituciones contribuyen a la satisfacción de las necesidades exhibidas por los colectivos de mayor vulnerabilidad.

Colombia no ha sido ajena al movimiento cooperativista que se está dando en el contexto global, donde este sector ha demostrado tener un gran auge impulsador de la economía. Esto se confirma a partir de los datos arrojados por la Confederación de Cooperativas de Colombia (Confecoop) (2013), en donde se demuestra el gran auge que han ostentado este tipo de instituciones en el territorio nacional, al registrar un total de 8.473 entidades que lograron registrar cerca de 6.7 millones de personas.

En lo que respecta a la intermediación financiera, se puede expresar que en el país 1.643 cooperativas se dedicaron en el 2012 a esta actividad, lo que en términos porcentuales significa el 25.6 nacional. En cuanto a los ingresos recibidos por las organizaciones cooperativistas financieras, un $47.2 \%$ se originaron para ese año del subsector de Ahorro y Crédito, demostrando la importancia que para la economía colombiana representan estas entidades (Confecoop, 2013).

La naturaleza social que caracteriza a las instituciones solidarias inmersas en el cooperativismo, no significa de ninguna manera que los procesos utilizados por los agentes encargados de la planeación, organización, dirección y control de sus recursos redunden en la ineficacia e ineficiencia; por el contrario al inclinarse por la materialización de objetivos de desarrollo socio empresarial, se requiere que en ellas confluyan mecanismos de gestión orientados hacia la generación de valor y la competitividad (Guzmán et al., 2015; Peraza et al., 2016).

De hecho, a través de un estudio efectuado por Bruque et al. (2002) se logró determinar que las organizaciones cooperativas pueden alcanzar mayores niveles de competitividad que las instituciones capitalistas, debido a que la participación activa de los asociados mediante la ejecución de procesos de gestión y toma de decisiones, puede mejorar sustancialmente las bases para el desarrollo de ventajas competitivas a partir de la integración y mejora de la calidad del capital humano.

Las cooperativas de ahorro y crédito como instituciones que operan desde el tercer sector, son un tipo de organización societaria que depende en gran medida de los activos de naturaleza intangible y en especial del conocimiento que fluye en el interior de ella; por esta razón, resulta de especial trascendencia que los estamentos encargados de la dirección de este tipo de entes entablen mecanismos de gestión que propendan por la generación de ventajas competitivas, a partir de la explicitación de todos aquellos conocimientos que se encuentran en su dimensión tácita, si es que quieren ser sostenibles en un escenario que requiere de un alto grado de responsabilidad social y especialización en los servicios ofrecidos a la sociedad (Seguí, 2007; Flores \& Ramírez, 2011). 
Sin embargo, Otálora y Vásquez (2016) lograron demostrar las carencias que presentan los sistemas de gestión estratégica utilizados por este tipo de entidades, con respecto a la generación de información útil y relevante para el desarrollo de estrategias competitivas. Esto señala que los procesos administrativos implementados en las cooperativas de ahorro y crédito, se fundamentan en las nociones experimentales de sus directivos, lo que podría limitar las posibilidades de crecimiento.

Dada la importancia que ha ostentado la gestión del conocimiento en la nueva economía, en ocasión a la generación de procesos que ubiquen a la organización hacia un desempeño competitivo y a la transcendencia de las instituciones cooperativas que ejecutan actividades de ahorro y crédito para los sistemas económicos actuales, el objetivo del artículo se ubica en el análisis de la relación entre la gestión del conocimiento y la competitividad en las cooperativas con sección de ahorro y crédito en Barranquilla.

Para alcanzar el objetivo general, se desarrolló una investigación con enfoque racionalista crítico y paradigma cuantitativo. Por otro lado, el alcance del estudio fue correlacional, el cual permitió determinar la relación existente entre las variables objeto de análisis. Así mismo, se empleó un diseño no experimental transversal correlacional causal y se requirió de datos tanto primarios como secundarios, los cuales fueron analizados mediante la utilización de medidas de dispersión, localización y coeficientes de correlación.

El artículo se divide en siete grandes apartados a través de los cuales se presenta en primera instancia la introducción. Más adelante, se fundamenta teóricamente la investigación desarrollada, considerando para esto los aportes efectuados por los principales referentes. Luego, se define el procedimiento metodológico que se consideró necesario para alcanzar el objetivo y se presenta el análisis de los datos y la discusión. Finalmente, se detalla las conclusiones, limitaciones del estudio y las contribuciones a futuras líneas de investigación.

Debido a que las cooperativas con sección de ahorro y crédito son agentes de naturaleza socio empresarial que dependen en gran medida de los activos intangibles y en especial del conocimiento tácito, la investigación aporta una descripción de la gestión del conocimiento en este tipo de instituciones y su vínculo con el desarrollo de estrategias competitivas que permitan identificar los factores clave de éxito.

\section{Perspectiva teórica de la gestión del conocimiento}

En la era post industrial la consecución de una posición competitiva sustentable, responde a las capacidades que posea la organización para desarrollar planteamientos estratégicos que permitan aprovechar las oportunidades del mercado y establezcan mecanismos de defensa ante las diferentes amenazas provenientes del entorno. Para Chang (2011) y Valenzuela (2008), los paradigmas administrativos de la tercera revolución industrial requieren que los estamentos directivos desarrollen procesos administrativos dirigidos a la gestión del talento humano, la calidad, las competencias, la innovación y el conocimiento. 
Debido a la importancia que han adquirido los activos intangibles no identificables en los diferentes informes financieros generados por la contabilidad, la gestión del conocimiento se ha establecido en una estrategia administrativa que garantiza sostenibilidad en el tiempo, presencia en el mercado y generación de valor (Castelló, 2002). Por otro lado, a partir de la utilización de mecanismos a través de los cuales se fundamenten las capacidades organizacionales para tomar decisiones con base en la transformación del conocimiento tácito en explícito, se pueden identificar aquellas variables que influyen directamente en el desempeño económico y social de la organización.

Inicialmente, Nonaka y Takeuchi (1995) abordan a la gestión del conocimiento como un proceso mediante el cual se fortalecen las habilidades organizacionales con respecto a la transformación y creación de conocimiento ${ }^{4}$ base para la generación de ideas innovadoras. Dicho procedimiento, se cumple a través de la materialización de cuatro fases llamadas sociabilización, externalización, combinación e internalización.

Por su parte, Sveiby (1997) considera a la gestión del conocimiento como uno de los mecanismos de administración empresarial de mayor relevancia de la sociedad actual debido a que a través de la aplicación económica de las capacidades individuales y colectivas de aprendizaje organizacional, las unidades económicas desarrollan habilidades institucionales para generar valor a partir de los activos de sustancia inmaterial.

Con la misma orientación teórica, Gates (1999) y Steib (1999) consideran que la gestión del conocimiento responde a un proceso de administración estratégica de los datos que fluyen dentro de la organización. Dicho paradigma administrativo, propende por la búsqueda, selección, organización y difusión de la información con el objetivo esencial de que el capital humano adquiera las capacidades necesarias para el desarrollo de sus funciones.

Para Brookings (1996); Nonaka y Takeuchi (1995); Wiig (1993); Bueno (1998); Davenport y Prusak (1998) y Archibold y Escobar (2015), el propósito final de la gestión del conocimiento en el entorno organizacional es el de construir estrategias relacionadas con la administración del capital humano, que permitan generar condiciones de satisfacción laboral y una cultura organizacional, propiciando un proceso sistemático de creación, desarrollo, compartimiento, difusión y medición del conocimiento con el objeto de transformar el capital intelectual en mayor competitividad.

Debido a la importancia del conocimiento para la materialización de los objetivos interpuestos por los estamentos directivos durante el transcurso del periodo operacional, las organizaciones deben establecer un plan estratégico constituido por prácticas institucionales que direccionen los mecanismos de gestión hacia la aplicación económica de los activos intangibles derivados de las capacidades de aprendizaje individual y colectivo. Todo lo anterior debe estar cimentado en una plataforma informática que posibilite la transferencia, clasificación y acumulación de los datos necesarios para la toma de decisiones.

4 Para Nonaka y Takeuchi (1995), en las organizaciones el conocimiento tácito hace referencia a las ideas, valores, intuiciones y emociones de capital humano. Por otro lado, el conocimiento explícito se refleja en las base de datos, formulas, manuales de procedimientos, principios y rutinas organizacionales. 
No obstante, al ser el conocimiento un activo dinámico que debe ser gestionado para evitar su fuga y asegurar a partir de él la optimización de los procedimientos internos, Gómez (2009) manifiesta que los estamentos encargados de la administración empresarial se encuentran obligados a implementar procesos orientados a la determinación del impacto que ejercen los activos basados en estos recursos de sustancia inmaterial, sobre la consecución de una posición competitiva en el mercado.

Para la descripción del proceso que deben implementar las organizaciones con el objetivo esencial de evaluar el grado en el cual el conocimiento propicia la obtención de resultados positivos desde una perspectiva financiera, social y ambiental a la vez que incrementa las capacidades de aprendizaje organizacional y de generación de valor a partir del capital intelectual, se tomará como referencia la postura teórica esgrimida por Gómez (2009), quien desarrolló un esquema compuesto por seis dimensiones orientadas a la evaluación de las capacidades empresariales para crear, identificar, adquirir, clasificar, almacenar, aplicar, actualizar, transferir y medir el conocimiento.

Para la fase creación del conocimiento Gómez (2009) tomó como referencia el modelo de gestión del conocimiento desarrollado por Nonaka y Takeuchi (1995), quienes manifiestan que en el interior de las organizaciones el conocimiento se genera a través de la interacción continua entre la dimensión tácita y explícita que presenta este activo de sustancia inmaterial. De acuerdo a los autores citados, este proceso se lleva a cabo en el contexto organizacional mediante un espiral integrado por cuatro etapas orientadas a la sociabilización, exteriorización, combinación e interiorización de las capacidades institucionales para generar ventajas competitivas a partir de la solución de las situaciones problemáticas que se presentan en el transcurso del periodo operacional.

Para la fase de Identificación y adquisición, Gómez (2009) utiliza los fundamentos teóricos desarrollados por Zack (1999), quien considera que el conocimiento representa una herramienta fundamental para la materialización de los objetivos propuestos. Por este motivo, resulta perentorio que los estamentos directivos efectúen procesos analíticos orientados a identificar el Know How que posee la institución para enfrentar la competencia.

Debido a que la verdadera utilidad del conocimiento responde a criterios relacionados con los resultados tangibles e intangibles derivados de su aplicación económica, resulta de vital importancia que existan procesos de almacenamiento acompañado de una adecuada categorización de la información explícita en la memoria organizacional, de acuerdo a criterios relacionados con las actividades que constituyen las áreas funcionales de la empresa, nivel jerárquico que poseen los datos, grado de divulgación y estructura tecnológica. De acuerdo al modelo de Gómez (2009), esto se desarrolla en la fase de almacenamiento y clasificación.

Dentro de los aspectos teóricos característicos de la dimensión aplicación y actualización, se resalta que la utilidad de aquellos activos intangibles no identificables estará supeditada a la capacidad que posean los estamentos directivos para integrar el cuerpo de conocimiento nuevo y existente con el objetivo esencial de optimizar la cadena de valor, tomar decisiones no programadas, desarrollar procesos de innovación, resolver situaciones problemáticas con efectividad y mejorar la cultura organizacional. En este contexto, adquiere especial 
transcendencia el capital intelectual como elemento indispensable para la generación de rutinas empresariales que propicien el desarrollo de ventajas competitivas (Gómez, 2009; Bueno, 1998).

El proceso de transferencia del conocimiento dentro del contexto organizacional, requiere de la utilización tanto de herramientas tecnológicas que faciliten su distribución, como de un capital humano que soporte los procesos de transmisión de todas aquellas experiencias adquiridas. Este escenario propicia el incremento del Know How institucional a partir de la explicitación de las capacidades individuales del capital humano (Gómez, 2009; Nonaka \& Takeuchi, 1995).

Finalmente, Gómez (2009) manifiesta que la medición hace referencia al proceso de evaluación del valor que se genera a partir de la aplicación económica del conocimiento. Por otro lado, Larios (2009) considera que en el entorno empresarial este proceso se constituye en la piedra angular para lograr que los procesos administrativos se establezcan como un medio de apoyo en la eficiente materialización de los objetivos interpuestos; en lo que respecta al capital intelectual, el autor conceptúa que su estimación permitirá identificar cuáles son los activos intangibles que posibilitaran el desarrollo de ventajas competitivas.

Por otro lado, debido a que las organizaciones se han catalogado a través del tiempo como un organismo social que propende por la satisfacción de las necesidades ostentadas por los Stakeholders, resulta de vital importancia que los agentes encargados de implementar procesos administrativos en su interior, propendan por el desarrollo de estrategias que le permitan enfrentarse a las dinámicas de los mercados inmersos en la sociedad del conocimiento, a través de la manipulación de variables como el capital intelectual, gestión del conocimiento y aprendizaje organizacional. En el siguiente acápite se desarrollará el constructo teórico de la competitividad empresarial.

\section{Constructo teórico de la competitividad empresarial}

En lo que respecta al desarrollo teórico conceptual de la competitividad Castellano et al. (2013) expresan que han existido a través de la historia diversas corrientes doctrinales que han intentado representar lo que significa esta variable dentro del contexto empresarial. Esta situación, fue la cadena causal del surgimiento de los múltiples estándares orientados a la medición de la posición competitiva de una organización, con respecto a los agentes que confluyen como rivales dentro del sector económico en donde opera.

Inicialmente, Porter (1991) consideró que la competitividad en el contexto empresarial hacía referencia al desarrollo de procesos internos que fundamentan la generación de productos y servicios que le permiten a la organización mantener o incrementar su participación en los mercados. Bajo esta perspectiva, esta variable se encontrará supeditada a la presencia de factores endógenos y exógenos que van a delimitar la estructuración de las estrategias corporativas.

Según Abdel y Romo (2004) la competitividad empresarial resulta de la implementación de procesos productivos y de gestión que le signifiquen a la organización la generación de ventajas distintivas producto de la utilización de 
recursos y capacidades con un alto grado de valor, escasez y excepcionalidad. Como resultado, la organización reflejará productos y servicios con características que le permitirán adquirir una posición competitiva en el mercado, con respecto a la competencia.

Finalmente, Porter (2008) y García et al. (2017) expresan que la competitividad dentro de las operaciones desarrolladas por las organizaciones se encuentra supeditada por la productividad, la cual es abordada como el valor del producto generado por una unidad de trabajo o capital. En este sentido, para identificar los niveles de competitividad de un agente económico se deben reconocer cuáles son los factores clave de éxito que determinan la generación de valor por parte de los agentes económicos y su sostenibilidad tanto en el mediano como en el largo plazo.

\section{Factores clave de competitividad en el contexto de las cooperativas}

Debido a que las organizaciones se ubican como agentes de naturaleza económica y social que interactúan constantemente con el entorno que las circunscribe, existen factores provenientes del medio que condicionan de una u otra manera su desempeño competitivo. De hecho, Garay (1998) argumenta que, para efectuar un análisis de la competitividad desde una perspectiva integral, resulta relevante tener en consideración tanto las variables endógenas como aquellos condicionamientos de la industria y la nación.

Para Acosta (1999) los diferentes niveles de competitividad que presentan las organizaciones que convergen en un mismo sector económico, responden a la presencia de los llamados Factores Claves de Éxito (FCE), los cuales son abordados por López (2007) como aquellos condicionamientos internos o externos que son absolutamente necesarios para que las estrategias competitivas fundamenten la materialización de los objetivos previamente establecidos.

El origen de los diferentes Factores Claves que determinan el nivel competitivo de una organización, posee múltiples clasificaciones taxonómicas producto de los diferentes estudios que se han desarrollado con respecto a la medición de la competitividad empresarial; no obstante, para el constructo teórico del presente trabajo de investigación se tomará como referencia la clasificación esbozada por Acosta (1999), para quien dichos componentes se agrupan en tres dimensiones que representan las variables macroeconómicas, sectoriales e internas que deben tener en cuenta los gerentes al momento de formular las estrategias.

De acuerdo a lo expresado por Llorente (2013), los Factores Clave de Éxito desde una perspectiva macroeconómica que condicionan la posición competitiva de los agentes empresariales, se originan de las variables derivadas del sistema económico, social y ambiental. Dichos elementos, son ajenos a las rutinas y prácticas empresariales toda vez a que confluyen en el macro entorno. Por este motivo, no pueden ser objeto de control al momento de implementar procesos productivos.

Para Porter (1990), los factores de la economía que afectan directamente la competitividad de los sectores económicos y el desempeño de las organizaciones que los integran, se encuentran relacionados con el estado actual de los factores de producción, el nivel de demanda que posee el bien o servicio ofertado por un 
segmento de la economía, la presencia de sectores alternativos que sean competitivos internacionalmente y las características normativas con respecto a la creación y gestión de empresas en el país.

El análisis de la realidad del sector industrial que circunscribe a la empresa, determina el rendimiento que pudiera llegar a tener en el mercado, debido a que los Factores Clave de Éxito desde la perspectiva sectorial direccionarán el establecimiento de las estrategias corporativas hacia la implementación de políticas relacionadas con los precios, el nivel de producción o la realización de inversiones (Llorente, 2013).

Para Porter (2008), la rentabilidad y competitividad determinan la estructura de los sectores en los cuales se dividen los sistemas económicos; dichas variables, se encuentran supeditadas por las amenazas de nuevos competidores, el poder de negociación que pudieran llegar a poseer tanto los clientes como los proveedores, la presencia de bienes o servicios sustitutos y la existencia de altos niveles de rivalidad entre las organizaciones pertenecientes a la industria.

Desde la asunción de los fundamentos teóricos desarrollados por Porter (1991), la explicación del origen de las ventajas competitivas se manifestaba a partir de las fuerzas del entorno. Sin embargo, a través de la teoría de recursos y capacidades de Penrose (1959) y Barney (1991) se direccionó el análisis de las causas del desempeño competitivo de las organizaciones hacia los diferentes factores internos que constituían los activos y habilidades empresariales.

En este sentido, Llorente (2013) expresa que la responsabilidad de la generación de valor en las diferentes organizaciones, se encontrará supeditada a la eficacia de las diferentes políticas empresariales y no de los factores claves de éxito inmersos en el entorno económico. En este escenario, el conocimiento como recurso de naturaleza intangible se constituye en un valioso activo capaz de direccionar a la organización hacia una posición competitiva en el mercado.

Las cooperativas, son un tipo de organización societaria en la cual el principal objetivo es la satisfacción de necesidades socioeconómicas de carácter colectivo. Es por este motivo, que el asociado toma una participación activa en el proceso decisorio relacionado con la gestión de la producción, prestación de servicios o comercialización. De hecho, Bruque et al. (2002) expresan que una característica del cooperativismo es el alto compromiso que adquiere el socio con el éxito competitivo de la empresa al ser proveedor de recursos tangibles e intangibles, gestor de las operaciones institucionales y cliente de la cadena de valor.

En este sentido, los factores claves del éxito competitivo de las organizaciones cooperativistas, se encuentran establecidos de acuerdo a lo arrojado en los estudios elaborados por Bruque et al. (2002); Montegut (2006) y Moyano et al. (2008), quienes hallaron evidencia empírica que soporta la hipótesis de que los recursos y capacidades de dichas organizaciones solidarias, se establecen como variables determinantes para la consecución de una posición competitiva en el mercado. En otras palabras, los componentes internos explican en mayor medida la competitividad de dichas instituciones, que los elementos que se establecen en el orden micro y macroeconómico.

A partir de esto, se identifica a la capacidad de reacción ante los requerimientos del asociado, participación de los socios en los resultados, adaptación del servicio basado en la calidad, eficiencia en la utilización de los recursos tecnológicos, 
correcta financiación, formación del capital humano, adecuada dimensión, grado de lealtad de los asociados y estructura de propiedad como aquellos factores clave del éxito competitivo en las cooperativas.

Con relación a la variable dimensión, Montegut (2006) manifiesta que su efecto en la competitividad de las organizaciones, se ve reflejado en el poder de negociación que se posee con respecto a los clientes y proveedores, la capacidad de adaptación de la empresa ante las exigencias del entorno y la reducción de los costes de producción o prestación de servicios al trabajar con base en economías de escala. En cuanto a las cooperativas, este factor se constituye en un importante indicador que mide el potencial con el cual se pueden generar beneficios socioeconómicos para los asociados.

Por su parte la política tecnológica utilizada por la organización, se transforma en un recurso estratégico capaz de ubicarla en una posición competitiva en el mercado, debido a que partir de ella los productos y servicios se constituyen en propuestas de valor para los clientes. En efecto, las herramientas tecnológicas son una fuente fundamental para el éxito competitivo de las instituciones cooperativas, en razón a que permiten actualizar los procedimientos internos a las exigencias ambientales, sociales y económicas de los asociados.

Por otro lado, el establecimiento de adecuadas políticas financieras tomando como referencia la realidad del entorno, tendrá un efecto directo en la consecución de una posición competitiva, independientemente al sector económico en el cual se encuentre inmersa la organización. En el caso específico de las cooperativas, las necesidades de recursos deben suplirse de acuerdo a las características de su actividad; sin embargo, para que este factor sea un elemento clave en la competitividad, el apalancamiento financiero debe fundamentarse en la satisfacción de las necesidades colectivas utilizando para ello herramientas de autofinanciación como el capital social, reservas, fondos de destinación específica o aportes de la sección de crédito.

Otro factor de competitividad en el contexto de las instituciones cooperativas, hace referencia al desarrollo de procesos y procedimientos internos que garanticen productos y servicios basados en la diferenciación. Por esa razón, la calidad como factor clave del éxito competitivo lleva consigo aumentos sostenidos en la productividad empresarial, las ventas de un periodo operacional a otro, la rentabilidad de las operaciones y la cuota de mercado.

Actualmente, los agentes empresariales afrontan presiones competitivas provenientes del entorno que requieren la formación de capacidades dinámicas que faciliten su adaptación a las constantes exigencias del entorno y la realización de innovaciones en todas sus dimensiones. En este escenario, el conocimiento se transforma en un recurso que incide positivamente en la competitividad empresarial. Por este motivo, las cooperativas requieren del desarrollo de estrategias a través de las cuales se pueda afrontar las exigencias del mercado a partir de la gestión de los activos intangibles no identificables.

Uno de los rasgos distintivos de las sociedades cooperativas es que el asociado desempeña de manera paralela el rol de propietario, proveedor, cliente y empresario capaz de participar activamente en las decisiones programadas y no programadas. En tal sentido, existe una relación positiva entre la capacidad que demuestre la institución para suplir los requerimientos del cliente, el grado de 
lealtad de los asociados y la estructura de sociedad con respecto a la consecución de una posición competitiva.

\section{Aspectos metodológicos de la investigación}

Para cumplir el objetivo general del artículo, se utilizó un enfoque epistemológico cuantitativo, debido a que se analizó la relación entre la gestión del conocimiento y la competitividad en las cooperativas de ahorro y crédito de Barranquilla, mediante el uso de técnicas numéricas propias de la ciencia estadística. Por otro lado, el alcance de la investigación se ubicó en el correlacional, toda vez que a que se utilizó el coeficiente de Pearson (r) para valorar el vínculo entre el desempeño competitivo de las organizaciones objeto de estudio y su aplicación económica del conocimiento (Hernández et al., 2014).

En lo que respecta al procedimiento sistemático utilizado por el investigador para observar, describir y explicar la realidad estudiada, se puede expresar que este se ubicó en las dinámicas de la deducción, la cual es abordada por Bernal (2010: 59) como aquella que consiste en "tomar conclusiones generales para obtener explicaciones particulares". Por otra parte, reconociendo el enfoque y alcance ostentado por la investigación, el diseño utilizado a fin de adquirir la información que se considera necesaria en la solución del objetivo expuesto, fue el no experimental transversal descriptivo, en razón a que se careció de control sobre las variables analizadas (Hernández et al., 2014).

Como instrumento de recolección de información primaria se utilizó un cuestionario con escalas ordinales tipo Likert y multinomiales, el cual posee un índice de confiabilidad del 0.944 sobre 71 elementos; esta situación, demuestra coherencia y consistencia en los resultados generados a partir su aplicación. La población, estuvo integrada por las cooperativas de ahorro y crédito de Barranquilla.

De esta manera se pudo establecer a través de información suministrada por la Cámara de Comercio, que en la ciudad de Barranquilla existen 32 cooperativas con sección de ahorro y crédito en el año 2017. Asimismo, manejando un nivel de error de la muestra del $5 \%$, un porcentaje estimado ubicado en $50 \%$ y un nivel deseado de confianza de $95 \%$, se puede expresar que la muestra necesaria para la recolección de información primaria, se ubica en 30 organizaciones solidarias, las cuales fueron seleccionadas mediante el Muestreo Probabilístico Aleatorio Simple. Finalmente, para analizar e interpretar los datos se utilizaron medidas de tendencia central e índices de correlación como el coeficiente $r$ de Pearson.

\section{Análisis de resultados}

Según Tamayo (2004), el análisis de resultados se presenta ante la sociedad como el proceso mediante el cual se convierten los fenómenos observados en datos científicos; de esta manera, se exhibe a continuación la discusión del estudio, tomando como referencia la información obtenida a partir de la aplicación del cuestionario y los parámetros metodológicos esgrimidos anteriormente. 


\subsection{Gestión del conocimiento en las cooperativas de ahorro y crédito}

Con el objetivo esencial de analizar evidencias empíricas relacionadas con la gestión del conocimiento en el contexto de las entidades solidarias estudiadas, se desarrolló un cuestionario con escala ordinal tipo Likert con seis opciones de respuesta, en donde 6 equivale a total acuerdo, 5 moderado acuerdo, 4 acuerdo, 3 moderado desacuerdo, 2 desacuerdo y 1 total desacuerdo. Por otra parte, las herramientas estadísticas que se consideraron necesarias para lograr este fin, fueron las medidas de tendencia central y dispersión como la media, mediana, moda y desviación estándar.

En el contexto de las instituciones estudiadas, se observa que el conocimiento se instituye en una herramienta para la consecución de los objetivos corporativos, debido a que existe conciencia el compendio de habilidades técnicas y profesionales que necesitan para solucionar las situaciones problemáticas, motivo por el cual distinguen las capacidades individuales del capital humano y las explicitan en manuales de procedimientos.

Lo anterior posee soporte empírico en los resultados obtenidos, toda vez a que la mediana establece que más del $50 \%$ de los encuestados consideran que la opción cuatro, acuerdo, representa su opinión ante las afirmaciones planteadas. De igual forma, la moda indica que esta categoría de respuesta fue el común denominador en las valoraciones efectuadas por las unidades de análisis. Para este indicador, la media aritmética refleja un promedio de respuestas ubicado en 4.56 con un índice de dispersión de 0.733 (Ver tabla 1). Estos hallazgos, concuerdan con lo expresado por Nonaka y Takeuchi (1995); Zack (1999) y Gómez (2009).

Por otro lado, los resultados demarcan que en las cooperativas con sección de ahorro y crédito, existen rutinas empresariales que propenden por el almacenamiento y clasificación de las experiencias y habilidades del capital humano, utilizando para ello criterios relacionados con la estructura jerárquica de la empresa y el nivel de complejidad que presenta. Lo anterior, con el objeto de definir herramientas apropiadas para su acumulación.

Las afirmaciones efectuadas, poseen sustento empírico a través de las medidas de tendencia central, debido a que la mediana determina que más del $50 \%$ de los encuestados se encuentran de acuerdo con las afirmaciones que integran el indicador clasificación y almacenamiento del conocimiento; de igual forma, la moda indica que la categoría de respuestas que caracterizó la opinión de los encuestados fue el 4, opción acuerdo. En este caso, el promedio de respuesta fue de 4.10 con un nivel de dispersión media ubicado en 0.734 (Ver tabla 1). Estos hallazgos, se constituyen en evidencia empírica que confirman lo expresado por Davenport y Prusak (1998) y Gómez (2009).

Además, se pudo evidenciar en las organizaciones solidarias estudiadas que la restructuración de los procesos internos y la toma de decisiones, se fundamenta en las habilidades y experiencias individuales que se han logrado explicitar a partir de la definición de agentes responsables. Esto evidencia la transcendencia del capital intelectual en su dimensión humana, para aplicar el cuerpo de conocimiento constitutivo de la memoria organizacional y el desarrollo de ventajas competitivas sostenibles. 
Lo descrito se fundamenta en los datos arrojados por el instrumento, puesto que la mediana indica que más del $50 \%$ de los encuestados marcaron la opción 4 , acuerdo, ante las afirmaciones que integraron el indicador aplicación y actualización del conocimiento; de igual forma, la moda demuestra que los funcionarios consideraron que el cuatro fue la categoría de respuesta de mayor representación de la realidad empresarial de su cooperativa. En este caso, la media aritmética fue de 4.20 con una desviación estándar de 0.813 (Ver tabla 1). Estas evidencias, soportan los fundamentos teóricos de Bueno (1998) y Gómez (2009).

En lo que respecta al indicador transferencia del conocimiento, los resultados demuestran que en las cooperativas con sección de ahorro y crédito de la ciudad de Barranquilla, los estamentos directivos propenden por el desarrollo de estrategias corporativas que contribuyan a este fin; dichas herramientas hacen referencia a las políticas de incentivos que pregonen el bien común, la constitución de comunidades de aprendizaje basados en el trabajo en equipo y la utilización de instrumentos electrónicos que fundamenten la explicitación de las habilidades individuales del capital humano.

Estas consideraciones poseen evidencia empírica en los datos arrojados por el instrumento, debido a que la moda y la mediana determinan que más del $50 \%$ de los funcionarios encuestados consideran que la opción 4, acuerdo, representa la realidad empresarial de las instituciones objeto de estudio; este escenario es soportado por la media, debido a que el promedio de respuesta se ubicó en 4.50 para el indicador transferencia del conocimiento, con una dispersión de 0.917 unidades, esto genera consistencia en los datos utilizados (ver tabla 1). Lo descrito armoniza con los fundamentos teóricos de Nonaka y Takeuchi (1995) y Gómez (2009).

Analizando el indicador empírico relacionado con la medición del conocimiento, los resultados demuestran que en las cooperativas de ahorro y crédito de Barranquilla, se efectúan auditorías internas a fin de evaluar el Know How con el objetivo de determinar si este es suficiente para medir el nivel de satisfacción de los asociados; sin embargo, se observa la ausencia de indicadores de gestión que permitan ejecutar este proceso con un alto grado de eficiencia.

En este sentido, se demarca la importancia de evaluar la utilidad del conocimiento en la satisfacción de las necesidades corporativas y reconocer cuáles son los activos intangibles no identificables que fundamentan la generación de ventajas competitivas; sin embargo, los resultados demuestran que en el contexto de las organizaciones estudiadas, no se considera necesario definir indicadores que soporten la ejecución de este proceso.

Al respecto, la moda revela que los encuestados consideraron que el 4, opción acuerdo, era la categoría de respuesta que se ajustaba a la realidad de la cooperativa en la cual se encuentra inmerso, en lo que respecta al desarrollo de auditorías internas cuyo objetivo se establece en la medición de la capacidad del cuerpo de conocimiento, para satisfacer las necesidades de los asociados; no obstante, esta medida de tendencia central revela que los funcionarios abordados están en moderado desacuerdo (Opción de respuesta 3) en lo referido a la utilización de indicadores orientados a la valoración de la utilizad del conocimiento (Ver tabla 1). Estos resultados, arrojan datos empíricos que soportan modelos teóricos como el de Gómez (2009) y Larios (2009). 
Tabla. 1. Gestión del conocimiento en las cooperativas de ahorro y crédito

\begin{tabular}{ccccc}
\hline Dimensiones & Moda Mediana & Media & $\begin{array}{c}\text { Desviación } \\
\text { Estándar }\end{array}$ \\
\hline $\begin{array}{c}\text { Creación, identificación y adquisición del } \\
\text { conocimiento }\end{array}$ & 4.56 & 4 & 4.00 & 0.733 \\
$\begin{array}{c}\text { Clasificación y almacenamiento del } \\
\text { conocimiento }\end{array}$ & 4.10 & 4 & 4.00 & 0.734 \\
$\begin{array}{c}\text { Aplicación y actualización del conocimiento } \\
\text { Transferencia del conocimiento }\end{array}$ & 4.20 & 4 & 4.00 & 0.813 \\
Medición del conocimiento & 3.90 & 4 & 4.00 & 0.917 \\
\hline
\end{tabular}

Fuente: Elaboración propia a partir de la encuesta aplicada (2017)

\subsection{Competitividad de las cooperativas de ahorro y crédito}

Para analizar evidencias empíricas relacionadas con la competitividad de las organizaciones solidarias que desarrollan actividades de ahorro y crédito en la ciudad de Barranquilla, se tomó como referencia los fundamentos teóricos desarrollados por Bruque et al. (2002); Montegut (2006) y Moyano et al. (2008), quienes a través de investigaciones llegaron a la conclusión de que la capacidad de reacción ante los requerimientos del asociado, la participación de los socios en los resultados, la adaptación del servicio basado en la calidad, la eficiencia en la utilización de los recursos tecnológicos, la correcta financiación, la formación del capital humano, la adecuada dimensión, el grado de lealtad de los asociados y la estructura de propiedad, se establecen como aquellos factores clave del éxito competitivo en las cooperativas.

En lo que respecta a la capacidad de reacción ante los requerimientos de los asociados, los resultados demarcan que el $90 \%$ de las instituciones solidarias con sección de ahorro y crédito en la ciudad de Barranquilla propenden por la cualificación del capital humano a fin de garantizar respuestas eficientes ante las necesidades ostentadas por los Stakeholders; por otro lado, el $87 \%$ de la muestra determinó que existen en su institución políticas internas que incentivan la reducción de los tiempos de respuesta ante las situaciones problemáticas. Finalmente, el 93\% de las unidades analizadas consideran los planes de formación empresarial como la base para garantizar su adaptación ante las condiciones del entorno (Ver gráfico 1). 
Gráfico. 1. Capacidad de reacción a los requerimientos del asociado.

Capacidad de reacción a partir de la cualificación del recurso humano

Incentivos a la reducción del tiempo en la resolución de problemas

Planes de formación que incentiban la capacidad de adaptación de los asociados

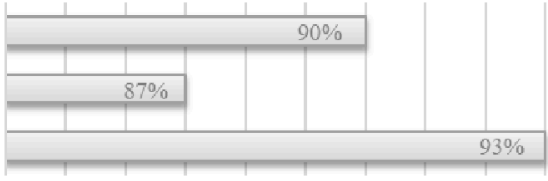

Fuente: Elaboración propia a partir de la encuesta aplicada (2017)

Analizando los resultados relacionados con el indicador participación de los asociados en los resultados obtenidos por la cooperativa, se denota que en el 93\% de las organizaciones encuestadas estos agentes son considerados dueños, gestores y usuarios de los servicios; por este motivo, estos participan activamente en el proceso de toma de decisiones; en efecto, un elemento clave en estas instituciones que garantiza su sostenibilidad, se ubica en el otorgamiento de créditos con tasas de interés por debajo de las que se manejan en el mercado financiero (Ver gráfico 2).

Gráfico. 2. Participación de los asociados en los resultados.

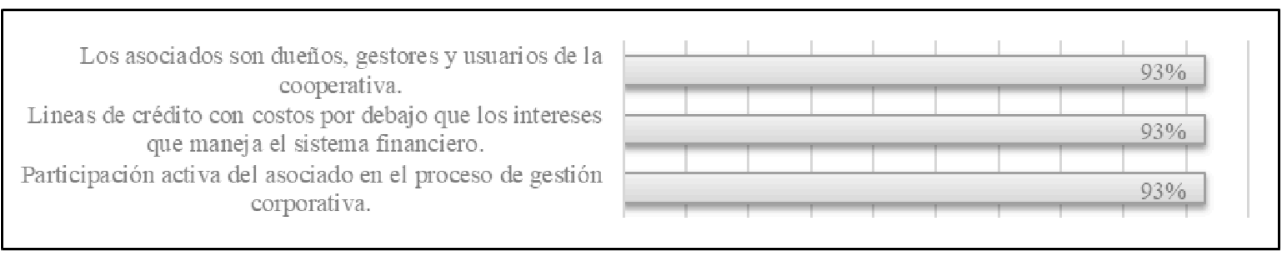

Fuente: Elaboración propia a partir de la encuesta aplicada (2017)

Una de las condiciones relevantes de las organizaciones en la actualidad, se establece en la satisfacción de las necesidades del mercado con un alto grado de eficiencia y calidad; para las instituciones encuestadas esta disposición resulta relevante en razón a que el $80 \%$ considera el sistema documental como herramienta clave para la toma de decisiones y el $87 \%$ manifiesta que existen en ellas un sistema de determinación de la información que se requiere. Además de lo anterior, el $77 \%$ posee una estructura de responsabilidad ante los procesos internos (Ver gráfico 3).

Por otra parte, en el $87 \%$ de las cooperativas de ahorro y crédito de la ciudad de Barranquilla, se asignan los recursos que sean necesarios con la finalidad esencial de asegurar la calidad en los procesos internos; además, el 90\% de las unidades empresariales encuestadas, determinan los procedimientos básicos para garantizar la prestación del servicio de ahorro y crédito a los asociados, de acuerdo a estándares mínimos de eficiencia. Para esto, el 60\% define tanto alineamientos, como objetivos estratégicos, y el $63 \%$ establece políticas corporativas orientadas a este fin (Ver gráfico 3). 
Gráfico. 3. Adaptación del servicio basado en la calidad número 1.

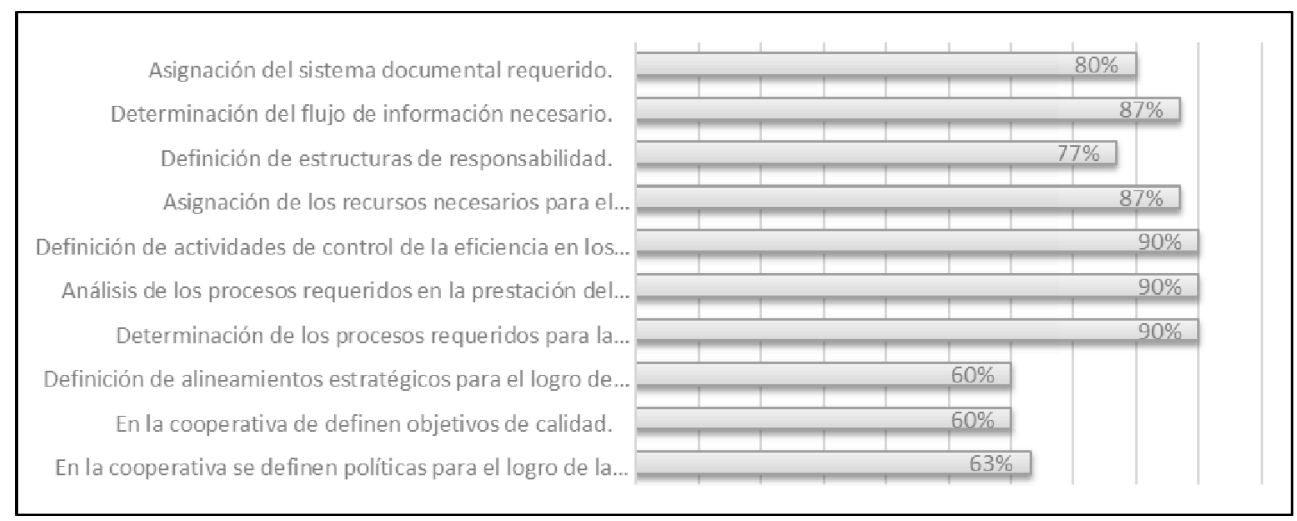

Fuente: Elaboración propia a partir de la encuesta aplicada (2017)

No obstante, a lo anterior, solo $3 \%$ de las cooperativas de ahorro y crédito de la ciudad de Barranquilla, asevera que posee un sistema de gestión de la calidad certificado de acuerdo a los estándares establecidos por las autoridades; ante este escenario, el $37 \%$ de la muestra expone que existen en su institución, proyectos para lograr las certificaciones correspondientes. Finalmente, el $37 \%$ de los encuestados manifiesta que no prevalecen en la institución solidarias procesos internos orientados a este objetivo, mientras que el $23 \%$ asevera que se implementan procedimientos internos que garantizan la eficiencia en los servicios prestados (Ver gráfico 4).

Gráfico. 4. Adaptación del servicio basado en la calidad número 2.

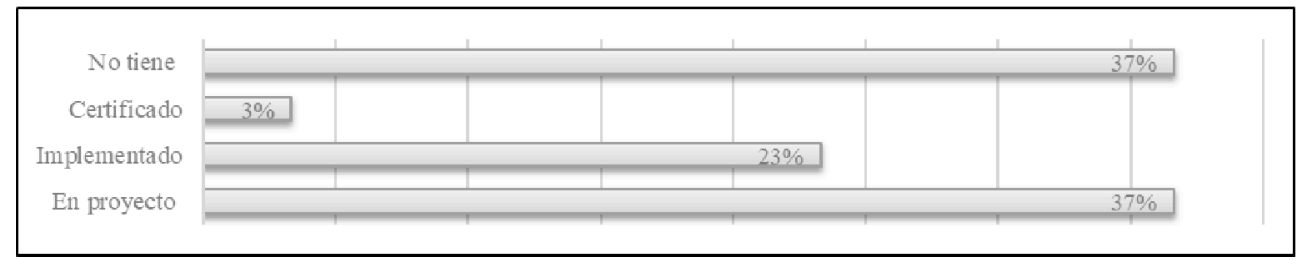

Fuente: Elaboración propia a partir de la encuesta aplicada (2017)

Los recursos tecnológicos, se establecen en factores clave para el éxito competitivo de las organizaciones, independientemente a si estas se constituyen con o sin fines de lucro; en cuanto a la situación de las cooperativas de ahorro y crédito de Barranquilla, el 93\% que integró la muestra estudiada considera que las herramientas tecnológicas, son el fundamento esencial para el cumplimiento de los objetivos corporativos, la prestación de servicios con un alto grado de eficiencia y el desarrollo de capacidades dinámicas para competir en un mercado cada vez más exigente y cambiante (Ver gráfico 5). 
Gráfico. 5. Eficiencia en la utilización de los recursos tecnológicos.

Hemramientas tecnológicas que soportan el cumplimiento de objetivos

Hetramientas tecnológicas que fundamentan la cali dad en

la prestación de servicios

Herramientas tecnológicas para competir en el mercado

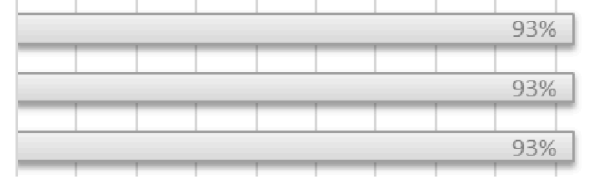

Fuente: Elaboración propia a partir de la encuesta aplicada (2017)

Para Montegut (2006), el apalancamiento financiero significa para las organizaciones cooperativas un factor que garantiza el éxito competitivo si se establecen las políticas adecuadas para garantizar este fin; en el caso de las instituciones solidarias que integraron la muestra estudiada, el 93\% encuentra en los estados financieros el instrumento contable a través del cual se soportan las decisiones de inversión y financiación; además de esto, el 90\% de los encuestados expresó que la cooperativa a la cual pertenece existen diversas herramientas para garantizar el cumplimiento de las obligaciones financieras (Ver gráfico 6).

Gráfico. 6. Correcta financiación número 1.

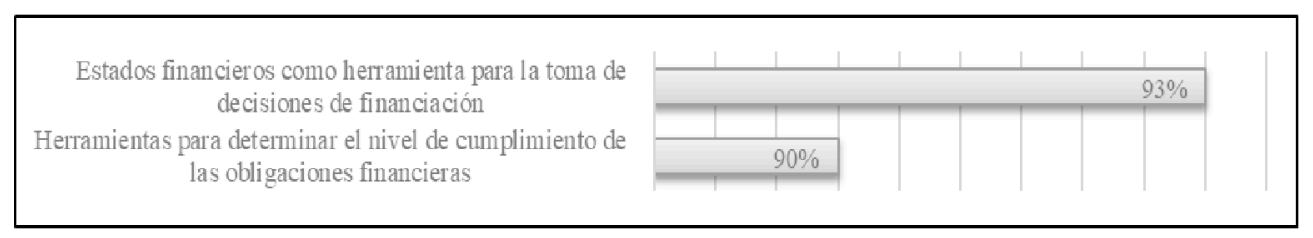

Fuente: Elaboración propia a partir de la encuesta aplicada (2017)

Además de lo anterior, Montegut (2006) manifiesta que el asociado al ser dueño, gestor y usuario de los servicios prestados por la cooperativa, la financiación se transformará en un factor clave de éxito en la medida en la cual esta se derive de recursos provenientes de ellos; en efecto, solo el $40 \%$ de las instituciones solidarias encuestadas se apalanca financieramente a través de este tipo de agentes económicos, mientras que el 47\% lo hace con obligaciones financieras a corto plazo; finalmente, resulta pertinente demarcar que para el 13\% de la muestra es importante hacerlo mediante la metodología del ahorro (Ver gráfico 7). 
Gráfico. 7. Correcta financiación número 2.

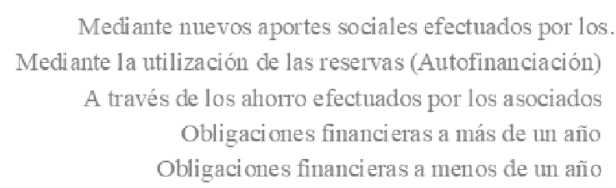

Mediante nuevos aportes sociales efectuados por los Mediante la utilización de las reservas (Autofinanciación)

A través de los ahorro efectuados por los asociados

Obligaciones financieras a más de un año

Obligaciones financieras a menos de un año

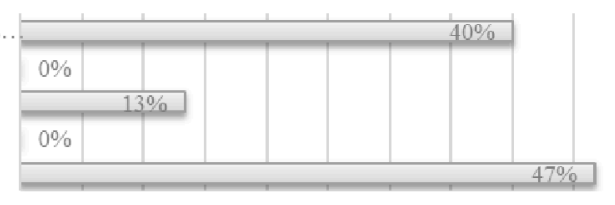

Fuente: Elaboración propia a partir de la encuesta aplicada (2017)

La formación como factor clave del éxito competitivo de las organizaciones solidarias inmersas en el cooperativismo, hace referencia al grado de cualificación que presente el capital humano encargado de su gestión empresarial; en el contexto de las cooperativas de ahorro y crédito de Barranquilla, el 53\% de los agentes encuestados aseveró que no existe en ellas un plan que garantice la capacitación constante de su capital humano. Como resultado relevante, se destaca el $20 \%$ de la muestra que manifiesta una implementación de dicho instrumento con periodicidad anual, mientras que el $7 \%$ lo hace trimestral. Por último, solo el $3 \%$ lo efectúa de manera mensual (Ver gráfico 8).

Gráfico. 8. Plan de formación.

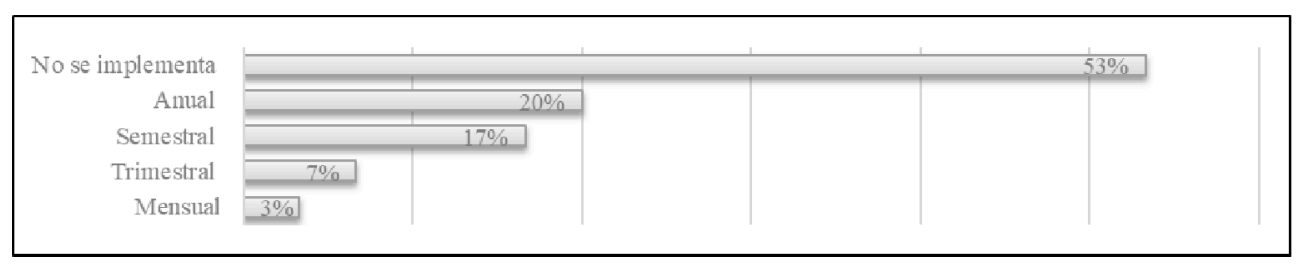

Fuente: Elaboración propia a partir de la encuesta aplicada (2017)

En el contexto de las organizaciones solidarias, la dimensión puede garantizar el éxito competitivo en la medida en la cual asegure un alto grado de apalancamiento financiero, mayor capacidad para tomar decisiones y utilización eficiente de los recursos internos; la primera variable aplicada para este fin hace referencia al Número de asociados. En el contexto de las cooperativas de ahorro y crédito de Barranquilla, el $70 \%$ poseen entre 51 y 200 socios, mientras que el $20 \%$ se encuentra en el rango de 201 a 500 . Por último, solo el $10 \%$ posee menos de 50 asociados (Ver gráfico 9). 
Gráfico. 9. Número de asociados en la cooperativa.

$$
\begin{aligned}
& \text { Más de } 1000 \text { socios } \\
& \text { De } 501 \text { a } 1000 \text { socios } \\
& \text { De } 201 \text { a } 500 \text { socios } \\
& \text { De } 51 \text { a } 200 \text { socios } \\
& \text { Menos de } 50 \text { socios }
\end{aligned}
$$

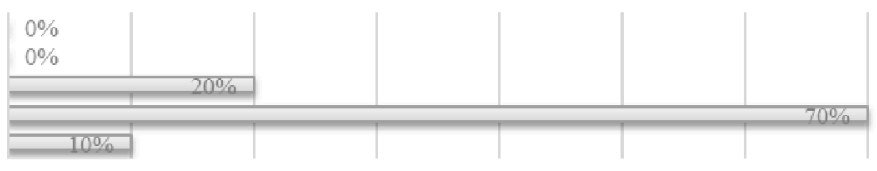

Fuente: Elaboración propia a partir de la encuesta aplicada (2017)

El volumen de los activos, es un elemento esencial para establecer la dimensión adecuada de la institución solidaria, debido a que la estructura financiera revela la eficiencia de los estamentos directivos en la utilización de los recursos empresariales; en efecto, el $70 \%$ de las cooperativas de ahorro y crédito de Barranquilla se encuentra en un rango de 501 a 5000 Salarios Mínimos Mensuales Vigentes (SMMLV); mientras que el 20\% se ubica en 5.001 a 15.000 SMMLV. Por otro lado, el 7\% controla recursos que ascienden los 15.001 SMMLV, mientras que solo el 3\% manifestó que la institución solidaria a la cual pertenece no supera los 500 SMMLV en lo que respecta a bienes corporativos de naturaleza tangible e intangible (Ver gráfico 10).

Gráfico. 10. Volumen de activos de la cooperativa.

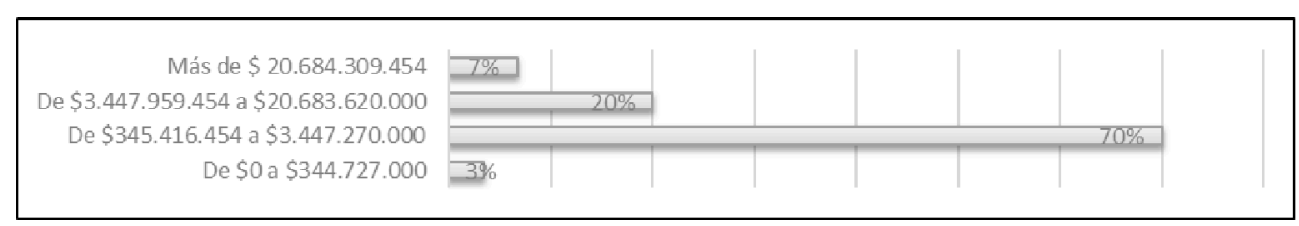

Fuente: Elaboración propia a partir de la encuesta aplicada (2017)

Finalmente, el número de asociados es un parámetro utilizado para determinar la dimensión de las cooperativas, y se transforma en un factor clave de éxito en la medida en la cual se le permita participar en la gestión de la institución solidaria; en el contexto de las cooperativas de ahorro y crédito de Barranquilla, los resultados de muestran que el 53\% que integró la muestra se encuentra en un rango de 0 a 10 asociados, mientras que el $43 \%$ manifestó encontrarse en el intervalo de 11 a 50. Es importante demarcar, que solo el 3\% declaró que sus socios sobrepasan los 201 (Ver gráfico 11). 
Gráfico. 11. Número de trabajadores asociados.

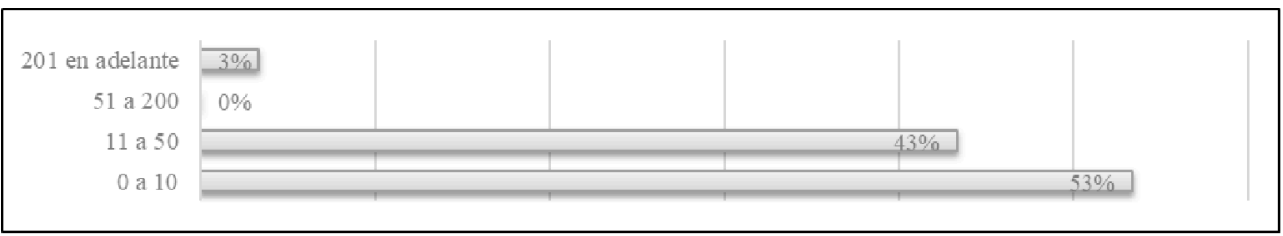

Fuente: Elaboración propia a partir de la encuesta aplicada (2017)

El último factor clave de éxito determina que existen en las instituciones solidarias utilizadas estrategias que garantizan la permanencia de los asociados en las cooperativas; de hecho, a partir de los resultados se infiere que el $80 \%$ de las cooperativas de ahorro y crédito de Barranquilla, los sistemas de información se constituyen en herramientas para determinar las necesidades de los agentes de mayor vulnerabilidad de la sociedad, mientras que el $83 \%$ utiliza las encuestas de satisfacción para lograr estos objetivos (Ver gráfico 12).

Gráfico. 12. Grado de lealtad de los asociados número 1.

Sistemas de infomación para conocer las necesidades de.

Realización de encuestas de satisfacción a los asociados

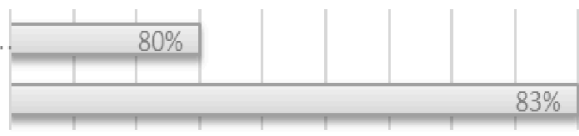

Fuente: Elaboración propia a partir de la encuesta aplicada (2017)

A efectos de garantizar la estancia permanente de los asociados en la institución, los estamentos directivos pueden utilizar diversas estrategias; Para Montegut (2006) la integración a otras instituciones solidarias es un factor clave de éxito en la medida en la cual fundamente la lealtad de los socios; en el contexto de las cooperativas de ahorro y crédito de Barranquilla, este tipo de asociación con otras organizaciones se ha efectuado en un $47 \%$ para disminuir costes de prestación de servicios, $43 \%$ para mejorar la calidad de los servicios prestados y $10 \%$ para completar el ciclo productivo (Ver gráfico 13).

Gráfico. 13. Grado de lealtad de los asociados número 2.

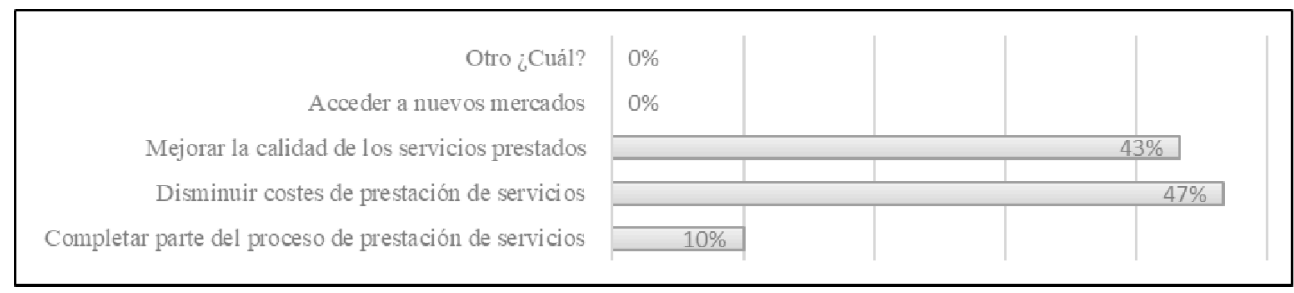

Fuente: Elaboración propia a partir de la encuesta aplicada (2017) 
Estos resultados, se constituyen en evidencia empírica que demuestra la competitividad de las cooperativas de ahorro y crédito de la ciudad de Barranquilla; para este efecto, se deduce la utilización de estrategias corporativas que demuestran la capacidad de estas instituciones para adaptarse a los requerimientos del asociado, la participación de estos agentes en los resultados obtenidos, la eficiencia en la utilización de las herramientas tecnológicas, la correcta financiación, una adecuada dimensión y una estructura empresarial que garantiza lealtad de los asociados

Sin embargo, existen en ellas debilidades que pueden llegar a afectar sus niveles competitivos. Estas carencias hacen referencia a la ausencia sistemas de gestión de calidad certificados, que garanticen procesos de prestación de servicios con un alto grado de eficiencia; por otro lado, no se implementan planes de formación que garanticen la generación de capital intelectual desde su dimensión humana. Existen altas probabilidades de que estas circunstancias, afecten el desempeño competitivo de las instituciones estudiadas.

\subsection{Relación entre la gestión del conocimiento y la competitividad en las cooperativas con sección de ahorro y crédito}

Para establecer la relación entre la gestión del conocimiento y la competitividad de las cooperativas de ahorro y crédito de la ciudad de Barranquilla, se tomó como referencia el coeficiente de correlación de Pearson, el cual es abordado por Hernández et al. (2014) como una prueba estadística que propende por la valoración de la relación existente entre dos variables estudiadas. Según los autores citados, este método propio de los análisis paramétricos arroja valores que pueden variar de -1 a 1 y se representa con la letra $r$.

Los resultados demuestran correlaciones inferiores a 0.3 entre el proceso de gestión del conocimiento y la competitividad de las cooperativas de ahorro y crédito de Barranquilla, lo que determina que no existe evidencia empírica que soporte los fundamentos teóricos desarrollados por Nonaka y Takeuchi (1995) y Gómez (2009), debido a que en el contexto de las instituciones estudiadas la sociabilización, exteriorización, combinación e interiorización de las capacidades individuales del capital humano no proporciona las bases fundamentales para el desarrollo de ventajas competitivas (Ver tabla 2). 
Tabla. 2. Correlación proceso de gestión del conocimiento y la competitividad

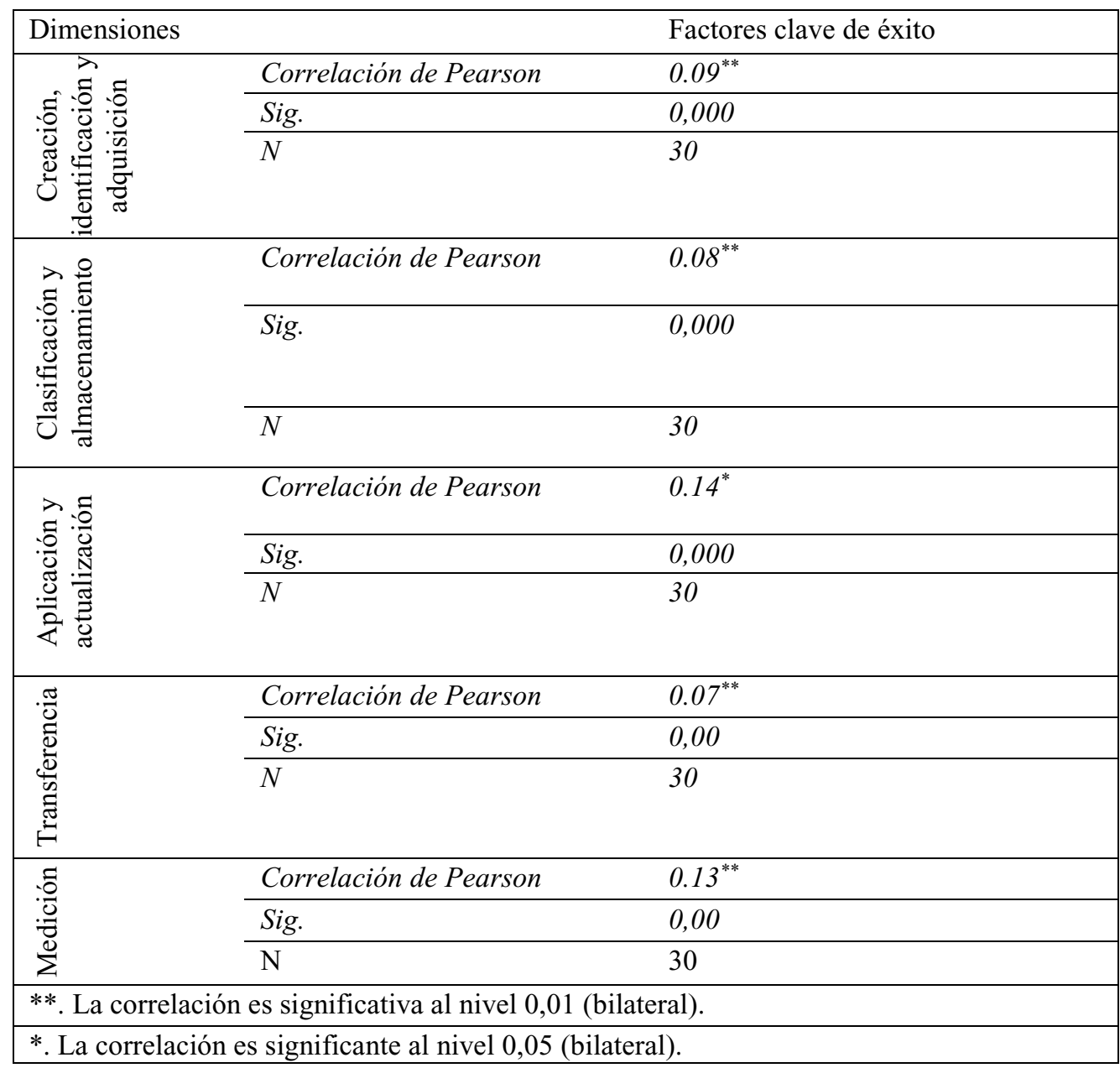

Fuente: Elaboración propia a partir de la encuesta aplicada (2017)

\section{Conclusiones}

En primera instancia, se evidencia el establecimiento de alineamientos estratégicos que propenden por la creación, identificación, adquisición, clasificación, almacenamiento, aplicación, actualización y transferencia del conocimiento; sin embargo, al momento de medir la utilidad de las capacidades explicitadas mediante la implementación de mecanismos de gestión, se denota la ausencia de indicadores que permitan determinar la eficiencia de la memoria organizacional en cuanto a la satisfacción de las necesidades ostentadas por los asociados.

Por otra parte, al analizar evidencias empíricas relacionadas con la competitividad en las cooperativas de ahorro y crédito de Barranquilla, se logró establecer el cumplimiento de gran parte de los factores clave de éxito definidos 
por Bruque et al. (2002); Montegut et al. (2006) y Moyano et al. (2008) para las organizaciones que desde la economía solidaria deseen ser competitivas. Lo anterior, permite concluir un desempeño empresarial que las ubica en los niveles de competitividad ideales para este tipo de organizaciones.

No obstante, aún existen aspectos corporativos que deben ser fortalecidos a efectos de alcanzar un nivel competitivo ideal; dichos factores hacen referencia a la ausencia de sistemas de gestión de calidad que presenten certificaciones relacionadas con la eficiencia de la institución solidaria, en lo que respecta a la prestación del servicio de ahorro y crédito. Además, no existen planes de formación que propendan por la cualificación y tecnificación del capital intelectual en su dimensión humana.

En este sentido, resulta relevante fortalecer los procesos de gestión empresarial de las cooperativas de ahorro y crédito, con la finalidad esencial de que estructuren estrategias corporativas que garanticen un desempeño competitivo exitoso, a partir de las capacidades individuales de aprendizaje organizacional y la presencia de procesos institucionales fundamentados en certificaciones que demuestren su eficiencia en la satisfacción de las necesidades que ostentan los agentes de mayor vulnerabilidad de la sociedad.

Por otro lado, se observan correlaciones positivas débiles entre los diferentes indicadores que integran las variables gestión del conocimiento y competitividad en el contexto de las cooperativas de ahorro y crédito de Barranquilla; lo que indica, que los alineamientos estratégicos llevados a cabo a fin de explicitar las capacidades implícitas de aprendizaje organizacional, no se relacionan con el desarrollo de estrategias competitivas orientadas al cumplimiento de las factores clave del éxito competitivo de las organizaciones solidarias.

Lo anterior, refuta los fundamentos teóricos de autores como Nonaka y Takeuchi (1995), De Geus (1998), Alvear y Ronda (2005), Sánchez et al (2007), Garzón y Fischer (2009) y Gómez (2009), quienes manifiestan que en el contexto de la sociedad actual, la gestión del conocimiento se establece como un paradigma de administración a partir del cual se construyen las bases para la generación de una posición competitiva en el mercado, a través de la concepción de ideas que propendan por la innovación en cada una de sus dimensiones.

Durante el desarrollo del estudio, se sentaron las bases para analizar los puntos convergentes entre la gestión del conocimiento y la competitividad en las cooperativas de ahorro y crédito, estableciendo de esta manera futuras líneas de investigación que propendan por la recolección de evidencia empírica que conlleve a la comprobación de aspectos teóricos relacionados con la influencia que ejerce la administración de los recursos intangibles en la resolución de problemas organizacionales. Sin embargo, las limitaciones generadas por los datos recolectados permiten recomendar el desarrollo de investigaciones orientadas a otros tipos de instituciones solidarias. 


\section{Referencias bibliográficas}

Abdel Musik, G. y Romo Murillo, D. (2004) Sobre el concepto de competitividad. Serie de documentos de trabajo en estudios de competitividad. México D.F., México: ITAM.

Acosta Molina, M. (1999) Factores internos y competitividad. Tesis Doctoral. Universidad de la Laguna, Santa Cruz de Tenerife, España.

Alvear Rodríguez, T. y Ronda Ceballos, C. (2005) Sistemas de Información para el Control de Gestión: Un apoyo a la gestión empresarial. Tesis de pregrado. Universidad de Chile, Santiago de Chile, Chile.

Archibold Barrios, W. y Escobar Castillo, A. (2015) Capital intelectual y gestión del conocimiento en las contralorías territoriales del Departamento del Atlántico. Revista Dimensión Empresarial, No1, Vol.13, pp. 133-146.

Barney, J. (1991) Firm resources and sustained competitive advantage. Journal of Management, $\mathrm{N}^{\circ}$ 1, Vol.17, pp. 99-120.

Bastidas Vialcanet, R. y Amat Salas, A. (2014) Efectos económicos de la primera aplicación de las normas contables adaptadas a la NIC 32 en las cooperativas. Revista de Contabilidad, $\mathrm{N}^{\circ}$ 2, Vol. 17, pp. 201-211.

Bernal Torres, C. (2010) Metodología de la investigación: Administración, economía, humanidades y ciencias sociales. Colombia, Bogotá: Pearson Educación. 384 p.

Brooking, A. (1996) Intellectual Capital Core Asset for Third. Madrid, España: Paidós empresa. 224 p.

Bruque Cámara, S., Hernández Ortiz, J., Moyano Fuentes, J. y Vargas Sánchez, A. (2002) ¿Son más competitivas las sociedades cooperativas? Un análisis en el sector de la distribución. Ciriec-España. Revista de Economía Pública, Social y Cooperativa, $\mathrm{N}^{0}$ 42, pp. 131-157.

Bueno Campos, E. (1998) El capital intangible como clave estrategica en la competencia actual. Boletin de estudios economicos, N¹64, Vol. 53, pp. 207-229.

Castellanos Domínguez, O., Ramírez Martínez, D., Fúquene Montañez, A., Quintero Amaya, R. y Fonseca Rodríguez, S. (2013) Competitividad: Apropiación y mecanismos para su fortalecimiento. Bogotá, Colombia: Universidad Nacional de Colombia. 242 p.

Castelló Muñoz, E. (2002) Los activos intangibles en la era del conocimiento. Boletin de estudios economícos, № 57, Vol. 176, pp. 197-226.

Castilla Polo, F., Sánchez Hernández, M., Gallardo Vázquez, D. y Ruiz Rodríguez, M. (2016) Diseño de un modelo de reputación para cooperativas oleícolas. Revista de Contabilidad, N ${ }^{\circ}$ 57, Vol. 19 1, pp. 154-167.

Chang, E. (2011) Gestión administrativa integral. En E. Cano, E. Chang, J. Jiménez, M. Sánchez, y P. Soto, Administración: Un enfoque hacia las instituciones educativas, pp. 129-150. Barranquilla, Colombia: Editorial Universitaria de la Costa, EDUCOSTA.

Confederación de Cooperativas de Colombia (Confecoop) (2013) Desempeño del sector cooperativo Colombiano 2012. Recuperado de http://confecoop.coop/images/informes_anuales/Informe_2012.pdf.

Davenport, T. y Prusak, L. (1998) Working Knowledge: How Organizations Manage What They Know. Boston, United State of America: Harvard Business Press. 199 p.

De Geus, A. (1998) Planning as learning. Harvard Business Review, No 4, Vol. 66, pp. 70 74.

Flores Uráez, M. y Ramírez Omaña, R. (2011) Intermediación de conocimiento: proceso de la gestión del conocimiento en cooperativas agropecuarias venezolanas. Revista venezolana de gerencia, $\mathrm{N}^{\circ} 55$, Vol. 16, pp. 458-473. 
Garay, L. (1998) Colombia: estructura industrial e internacionalización 1967-1996. En Competitividad. Bogotá, Colombia: Departamento Nacional de Planeación, Colciencias y Consejería Económica y de Competitividad. 630 p.

García Ochoa, J., León Lara, J. y Nuño De La Parra, J. (2017) Propuesta de un modelo de medición de la competitividad mediante análisis factorial. Contaduría y Administración, No 3, Vol. 62, pp. 775-791.

Garzón Castrillon, M. y Fischer, A. (2009) El aprendizaje organizacional en República Dominicana y Colombia. Pensamiento y gestión, No 26, pp. 238-278.

Gates III, W. (1999) Los negocios en la era digital. Barcelona, España: Plaza y Janés. 608 p.

Gómez Hernández, M. (2009) Desarrollo de un modelo de evaluación de la gestión del conocimiento en empresas de manufactura. Tesis doctoral. Universidad Politécnica de Madrid, Madrid, España.

Guzmán Alfonso, C., Santos Cumplido, F. y De La O Barroso González, M. (2015) Cooperativismo, factor empresarial y desarrollo económico: propuesta de un modelo teórico de enlace. REVESCO. Revista de Estudios Cooperativos, $\mathrm{N}^{\mathrm{o}} 122$, pp. 110-134. DOI: $10.5209 /$ rev_REVE.2016.v122.52018.

Hernández Sampieri, R., Fernández Collado, C. y Baptista Lucio, P. (2014) Metodología de la investigación. México D.F., México: Mc Graw Hill.

Larios Prado, J. (2009) El capital intelectual: Un modelo de medición en las empresas del nuevo milenio. Criterio Libre, $\mathrm{N}^{\mathrm{o}} 11$, Vol. 7, pp. 101-121

Llorente García, I. (2013) Análisis de competitividad de las empresas de acuicultura. Aplicaciones empíricas al cultivo de la Dorada (Sparus Auratha) y la lubina (Dicentrarchus labrax) (Tesis Doctoral). Universidad de Cantabria, Santander, España.

López Trujillo, M. (2007) Planeación estratégica de tecnologías informáticas y sistemas de información. Caldas, Colombia: Universidad de Caldas. 131 p.

Montegut Salla, Y. (2006) Análisis de los factores explicativos del éxito competitivo en las almazaras cooperativas catalanas (Tesis doctoral). Universitat de Lleida, Cataluña, España.

Monzón Campos, J. (2012) La globalización y el futuro de las cooperativas. Economía solidaria: Identidad, desafíos y estrategias. Valencia, España: CIRIEC, Centro Internacional de Investigación e Información. 440 p.

Moyano Fuentes, J., Puig Blanco, F. y Bruque Cámara, S. (2008) Los determinantes de la competitividad en las cooperativas. Ciriec-España. Revista de Economía Pública, Social y Cooperativa, No 61, pp. 233-249.

Nonaka, I. y Takeuchi, H. (1995) The knowledge creation company. New York, United States Of América: Oxford University Press. 318 p.

Otálora Beltrán, J. y Vásquez Peñaloza, L. (2016) Metodología ABC para el fortalecimiento de la gestión de costos en las cooperativas de ahorro y crédito de Barranquilla (Investigación financiada por COLCIENCIAS convocatoria 702 de 2015 y la Universidad de la Costa Convocatoria 11 de 2015). Universidad de la Costa, Barranquilla, Colombia.

Otálora Beltrán, J., Olaya, D., Borda Viloria, J. y Escobar Castillo, A. (2016) Efectos de las NIC 32 en los instrumentos de patrimonio: un estudio de cooperativas colombianas. Revista Venezolana de Gerencia (RVG), No 76, Vol. 21, pp. 653-672.

Penrose, E. (1959) The Theory of the growth of the firm basic. Londres, United Kingdom: Basic Blackwell. 249 p.

Peraza Castañeda, E., Gómez García, J. y Aleixandre Mendizábal, G. (2016) Los factores determinantes del comportamiento innovador de las cooperativas: un análisis para el 
caso de Castilla y León. REVESCO. Revista de Estudios Cooperativos, Vol. 122, № 3, pp. 252-284. DOI: 10.5209/rev_REVE.2016.v122.52025.

Porter, M. (1990) ¿Dónde radica la ventaja competitiva de las naciones? Harvard-Deusto Business Review, № 3, Número extra, pp. 3-26.

Porter, M. (1991) La ventaja competitiva de las naciones. Buenos Aires, Argentina: Vergara Editor S.A. 1020 p.

Porter, M. (2008) Las cinco fuerzas competitivas que le dan forma a la estrategia. Harvard Business Review, No 1, Vol. 86, pp. 58-77.

Sánchez Medina, A., Melián González, A. y Hormiga Pérez, E. (2007) El concepto del capital intelectual y sus dimensiones. Investigaciones Europeas de Dirección y Economía de la Empresa, № 2, Vol. 13, pp. 97-111.

Seguí Mas, E. (2007) La gestión del capital intelectual en las entidades financieras. Caracterización del capital humano en las cooperativas de crédito (Tesis doctoral). Universidad Politécnica de Valencia, Valencia, España.

Steib, N. (1999) Gestión del conocimiento: Algo más que información. Training \& Development Digest, $\mathrm{N}^{\mathrm{o}} 10$, pp. 58-59.

Sveiby, K. (1997) The new organizational wealth. San Francisco, United States of America: Berrett-Koehler Publishers, Inc. 220 p.

Tamayo y Tamayo, M. (2004) El proceso de investigación científica. México D.F., México: Limusa.

Valenzuela, L. (2008) Gestión empresarial orientada al valor del cliente como fuente de ventaja competitiva. Propuesta de un modelo explicativo. Estudios gerenciales, $\mathrm{N}^{\mathrm{o}} 109$, Vol. 24, pp. 65-86.

Wiig, K. (1993) Knowledge foundations: thinking about thinking-how people and organizations create, represent and use of knowledge. Arlington, United States of America: Schema Press. 471 p.

Zack, M. (1999) Managing codified knowledge. Sloan management review, № 4, Vol. 40, pp. $45-58$. 